\title{
Critical Thinking and Iranian EFL Context
}

\author{
Mansoor Fahim \\ Islamic Azad University, Science and Research Branch, Tehran, Iran \\ Email: dr.mfahim@yahoo.com \\ Mehrshad Ahmadian \\ Islamic Azad University, Science and Research Branch, Tehran, Iran \\ Email: mehrshadahmadian@gmail.com
}

\begin{abstract}
The advent of the information diffusion emanating from the information technology of the third millennium along with the revamped concept of literacy and intellectual understanding, and the demand for accountability as one of the prerequisites of modern societies has given birth to a movement resting on the idea that schools should be less concerned with imparting information and requiring the memorization of empirical data. Dealing with the extraordinary challenges of today's information society requires autonomous citizens equipped with "critical competence" (Feuerstein, 1999) whose meta-knowing is to be ameliorated through curriculum. The present study is an attempt to sketch the concept of critical thinking as a viable alternative in language education in Iranian EFL context. First, a number of definitions, along with the dimensions, of the concept from various scholars' viewpoints are put forward. Second, the typical features of critical thinkers and what resources they need are introduced. Third, the relation between critical thinking and learner autonomy is examined. Fourth, the relation between critical thinking and the instructional process is investigated. And finally, the issue from both theoretical and pedagogical standpoints in the contemporary Iranian EFL context is reviewed.
\end{abstract}

Index Terms - autonomy, critical thinking, Iranian EFL Context, meta-knowing

\section{INTRODUCTION}

Traditionally, it was thought that higher education led to literate and sophisticated individuals able to deal with the intricacies in their careers and personal lives since it was believed that education, and higher education in particular, sowed the seeds of much needed intellectual abilities rendering informed and successful citizens. However, with the advent of the information diffusion emanating from the information technology marking the onset of the third millennium, the newly-clothed concept of literacy and intellectual understanding, and the demand for accountability as one of the prerequisites of modern societies (Kuhn, 1999), academically successful students are no longer solely defined as individuals who are able to memorize facts and learn fixed routines and procedures, instead as individuals who can pool their resources to think critically and creatively both when they run into difficulties and about what they are learning (Chaffee, 1992).

If today's learners are to effectively deal with complex changes, increased demands, intellectual challenges, and greater accountability of the modern life, they must become skilled in higher level thinking and reasoning abilities. Skills in critical thinking can pave the way for the necessary broader outlook, creative solutions and multiple pathways needed for successful quality improvement initiatives. Therefore, as Huitt (1998) pronounced, critical thinking is a very important element of schooling in the $21^{\text {st }}$ century since in the information age, thinking plays a significant role in one's success in life. He further says that the movement toward the information age has shifted attention to good thinking as a significant element of life success. These changing conditions require new outcomes, such as critical thinking, to be embarked upon as a focus of schooling (Rezaei et al., 2011).

In spite of the fact that critical thinking abilities, such as solving problems, generating and organizing ideas and concepts, designing systematic plans of action, constructing, analyzing and evaluating arguments, exploring issues from multiple perspectives, and critically evaluating the logic and validity of information, are clearly needed for academic study and future career preparation, and even though teachers are eager to teach critical thinking as an educational ideal, critical thinking is barely taught explicitly and systematically within the educational framework (Chaffee, 1992). Routinely, the trend practiced in the academic world views education as the transfer of information from the full container - the teacher - to the empty container - the students - through the funnel of teaching. The task of the teacher in this view of education is to first and foremost cover the content of instructional materials rather encourage them to ponder over what they are learning. Teachers are regarded as the source of knowledge, the know-all, who are going to deliver another generation of passive know-it-alls, stuffed with what-to-do information, rather rendering an active, dynamic generation equipped with the much needed know-how discovering and exploring issues (Schafersman, 1991). Hence, the old view of education does not live up to the demands of the sophisticated modern societies which require leadership, management and decision skills among others for its citizens so that they can 
develop a progressive understanding of the process used in their field of study or career to both generate and think about information (Paul, 1990).

The current paper aims to review the literature on critical thinking, examine the dimensions of critical thinking, find out who is a critical thinker and what resources they need, examine the relation between critical thinking and learner autonomy, investigate the relation between critical thinking and the instructional process, and finally reviews the issue from both theoretical and pedagogical standpoints in the contemporary Iranian EFL context.

\section{CRITICAL THINKING}

What do critical thinking proponents generally have in mind when they talk about critical thinking? What skills do individuals accomplish in to be critical thinkers? How does this critical thinking accomplishment manifest itself? What are the components or states of such accomplishment? Viewed as an accomplishment means that not just any thinking however aimed at deciding what to believe or do can count as critical thinking. This suggests that thinking about what to believe or do must meet appropriate standards if it is to be regarded as critical thinking (Bailin et al., 1999). Thus, it seems relevant here to approach these questions through considering what types of thinking and standards per se educators typically would/would not regard as critical thinking.

As a concept, critical thinking has been elaborated in several ways. A major influence in critical thinking traces back to the work of the American educational philosopher John Dewey. To John Dewey, schools are laboratories of human development in arranged environments. Dewey held that the goal of education could only be development (or what he called "growth"); Education "means supplying the conditions which foster growth" (Dewey, 1916, as cited in Kuhn, 1999), not toward a predetermined end but rather in the direction of "an increase in the range and complexity of situations to which the child is capable of applying reasoned inquiry" (Cahan, 1994, as cited in Kuhn, 1999). In fact, the educator's task is seen as a process of connecting with the young child's interests and purposes, but that one could not stop there. Dewey said, "The real problem of intellectual education is the transformation of more or less casual curiosity and sporadic suggestion into attitudes of alert, cautious, and thorough inquiry" (Dewey, 1933, as cited in Kuhn, 1999).

Reviewing the many definitions of critical thinking, Richard Paul (1990) delineated it as:

Critical thinking is disciplined, self-directed thinking which exemplifies the perfections of thinking appropriate to a particular mode or domain of thought. It comes in two forms. If disciplined to serve the interests of a particular individual or group, to the exclusion of other relevant persons and groups, it is sophistic or weak sense critical thinking. If disciplined to take into account the interests of diverse persons or groups, it is fair-minded or strong sense critical thinking.

Taking a closer look at the above-mentioned definition, one would find out that the definition highlights three crucial dimensions of critical thought: 1) the perfections of thought; 2) the elements of thought; and, 3) the domains of thought. According to Paul (1990), in thinking critically we use our command of the elements of thought to adjust our thinking to the logical demands of a type or mode of thought. As we come to habitually think critically in the strong sense we develop special traits of mind: intellectual humility, intellectual courage, intellectual perseverance, intellectual integrity, and confidence in reason. A sophistic or weak sense critical thinker develops these traits only narrowly in accordance with egocentric and sociocentric commitments. By perfections of thought, Paul refers to features such as clarity, accuracy, adequacy, specificity, consistency, precision, and fairness.

Paul is critical of the definitions of other educational philosophers, for instance, Ennis' (1987; Norris \& Ennis, 1989, as cited in Paul, 1990) definition of critical thinking as "reasonable and reflective thinking concerned with what to do or believe" or Siegel's (1988, as cited in Paul, 1990) definition as thinking "appropriately moved by reasons", since Paul believes that these definitions rely on concepts such as reasonableness or reflectivity that are not themselves well defined.

The second position put forward here belongs to Kuhn (1999) who holds that developing cognitive competencies most relevant to critical thinking are metacognitive - rather than cognitive - competencies. Metacognitive skills are higher-order meta-knowing skills which help individuals to know about their own and that of others' knowing. As such, they are in contrast to lower-order cognitive skills which enable individuals to know about the world since "thinking about one's thought - in contrast to simply engaging in it - opens up a whole new plane of cognitive operations that do not exist at a simple first-order level of cognition" (Kuhn, 1999).

Kuhn's meta-knowing entails three broad categories: metastrategic, metacognitive and epistemological. Briefly elaborating, the distinction between metastrategic and metacognitive knowing is the same as the widely-employed dichotomy in cognitive psychology between procedural knowing (knowing how) and declarative knowing (knowing that): Procedural or strategic knowing entails the exercise of strategies to achieve certain goals, thus invoking a metastrategic form of knowing which selects and monitors the strategies from the repertoire of potentially available strategies; Metacognitive knowing operates on the basis of declarative knowledge. Simply put: What do I know, and how do I know it? Finally, epistemological knowing is related to an individual's broader understanding of knowledge and knowing: "It has both a general, philosophical aspect - How does anyone know? - and a personal aspect - What do I know about my own knowing?" (Kuhn, 1999).

The development of metacognitive understanding is essential to critical thinking because "critical thinking by definition involves reflecting on what is known and how that knowledge is justified" (Kuhn, 1999). Therefore, 
individuals with well-developed metacognitive skills take control of their own beliefs so that they can exercise conscious control over their evolution in the face of external influences. In other words, they both know what they think and can justify why.

Metastrategic skill is also essential to critical thinking since this skill help individuals apply consistent standards of evaluation across time and situations and do not fall for one favored assertion as more probable than its alternatives because of its favored status; in other words, these individuals resist the temptation of "local interpretation" (Klahr, Fay, \& Dunbar, 1993, as cited in Kuhn, 1999) of an isolated piece of evidence as supportive since context to which it belongs is absent in such an interpretation.

Last but not least, the development of epistemological understanding plays the pivotal role among the constituents of critical thinking. Epistemologically speaking, there are three stances: the absolutists who conceive that knowledge is entirely objective, certain, and simply accumulates, unconnected to the human minds that do this knowing; the multiplists who conceive that knowledge is entirely subjective, subject only to the tastes and wishes of the knower; and finally the evaluative epistemology, in which all opinions are not equal and knowing is understood as a process that entails judgment, evaluation, and argument (Kuhn, 1991, as cited in Kuhn, 1999).

To evaluative epistemologists some views can be more right than others. They weigh alternative claims in a process of reasoned debate as the path to informed opinion, and they understand that arguments can be evaluated and compared based on their merit (Kuhn, 1991, as cited in Kuhn, 1999); as a result, to absolutists and multiplists critical thinking skills are taxed to a lesser extent than those of the evaluative epistemologists.

Kuhn suggests that developing competence in all three categories of meta-knowing entails attention as a major component of cognitive development. As a result of such development, thought becomes increasingly aware of itself and under the individual's control. If one is to "know how one knows", one should take charge of one's own knowing, of deciding what to believe and why and of updating and revising those beliefs as one regards much needed. To get to this high level of awareness and control of their own thinking is arguably the most important way in which people both individually and collectively take control of their lives (Kuhn, 1999).

Now one question arises: Is critical thinking limited to the cognitive aspect of reasoning? Or does the affective side of individuals have a say too? Mc Peck (1981, as cited in Garrison, 1991) conceives of critical thinking as involving both a propensity and skill - "one must develop the disposition to use those skills", hence, teaching someone to be a critical thinker entails both the cognitive and the affective domains of reasoning. Furthermore, Brookfield (1987, as cited in Simpson \& Courtney, 2002) proposes that critical thinking entails more than cognitive skills, such as logical reasoning or scrutinizing arguments. Brookfield agrees that emotions are paramount to the critical thinking process, because as one attempts to think critically and assist others to do so, one cannot help but become conscious of the importance of one's emotions to this activity (Simpson \& Courtney, 2002).

As such, critical thinking comprises two dimensions: (a) cognitive skills and (b) affective dispositions. Having the requisite cognitive critical thinking skills is essential to being a good critical thinker, but it is not enough. The concept of critical thinking has also to do with a set of personal attitudes or dispositions that can be used to describe an individual who is inclined to use critical thinking. Therefore, in thinking critically, not only does a person attempt to determine judiciously what to do or what to believe, but a person is also able to apply the core critical thinking skills to one another. In other words, in thinking critically, one may analyze one's own inferences, explain one's own interpretation or evaluate one's own analysis (Simpson \& Courtney, 2002).

A word of caution needs to be mentioned here. Different scholars have their own varying definitions for critical thinking with certain unique elements such as knowledge, active argumentation, reasoning, initiative, intuition, application, analyzing complex meanings, identification of problems, seeking alternatives and making related value judgments. However, critical thinking is substantially larger than the sum of its parts, because it is a developmental process - an orientation of mind -, rather a static product or method to be learned, that promotes attitudes to continuously explore, redefine or understand (Simpson \& Courtney, 2002).

\section{CRITICAL THINKER}

Prior to answering this question, let's take a look at who an uncritical thinker is. The uncritical thinker is often "unclear, imprecise, vague, illogical, unreflective, superficial, inconsistent, inaccurate, or trivial" (Paul, 1990). If one is going to move away from being an uncritical thinker and become a critical thinker, s/he requires some command of the elements of thought. These elements include an understanding of and an ability to formulate, analyze, and assess:

1. The problem or question at issue;

2. The purpose or goal of the thinking;

3. The frame of reference or points of view involved;

4. Assumptions made;

5. Central concepts and ideas involved;

6. Principles or theories used;

7. Evidence, data, or reasons advanced;

8. Interpretations and claims made;

9. Inferences, reasoning, and lines of formulated thought; and 
10. Implications and consequences which follow. (Paul, 1990)

Brookfield (1987, as cited in Simpson \& Courtney, 2002) suggests that critical thinkers are typically individuals who are involved in productive and positive activity, in that they are actively involved with life and perceive themselves as creative and being re-creative in aspects of their personal, workplace and political lives. Furthermore, critical thinkers view their thinking as a process, rather than an outcome: A critical thinker is continually questioning the veracity of assumptions since critical thinking is not a static phenomenon. As King (1995) believes, a critical thinker has an "inquiring mind." Good (critical) thinkers are good questioners. Whatever they see, hear, read, or experience, they are constantly analyzing it, puzzling over its significance, searching for explanations, and speculating about relations between that experience and what they already know (king, 1995).

\section{INTELleCtuAl ResourCES TO BE A CRITICAL THINKER}

The best way to characterize who a real critical thinker might be is in terms of the required intellectual resources. These are as follows:

\section{(1) Background knowledge}

The quality of thinking individuals are able to do about a particular problem or question is determined by what they already know about it and about the context in which it must be resolved. Moreover, critical thinking always takes place in the context of already existing concepts, beliefs, values, and ways of acting. This context plays a crucial role in specifying what will count as reasonable application of standards and principles of good thinking. Hence, the depth of this background knowledge is a significant determinant of the degree to which they are capable of thinking critically in that area (Bailin et al., 1999).

\section{(2) Operational knowledge of the standards of good thinking}

As it was mentioned earlier, there need to be some standards in carrying out thinking tasks of critical thinking; otherwise, it would be haphazard. Therefore, the operational level of knowledge of the standards that govern critical deliberation and judgment is essential for anyone who would embark on thinking critically. Two kinds of standards seem relevant here: (1) standards that are relevant to judging intellectual products (e.g. arguments, theories, legal judgments, work of art), and (2) principles that are relevant to guiding practices of deliberation or inquiry (Bailin et al., 1999). In other words, one should:

- consider as many plausible alternative courses of action as is reasonable given the context of the decision, its significance, and one's prior reasoning about similar decisions;

- attempt to discover and take into account as much relevant information about the nature and consequences of each alternative as is reasonable given the context of the decision; and

- make a reasonable attempt to acquire an awareness of the point of view and presuppositions underlying one's thinking, and the possible biases to which this may give rise.(Coombs, 1997, as cited in Bailin et al., 1999)

\section{(3) Heuristics}

To effectively deal with thinking tasks, the critical thinker requires a rich repertoire of heuristic devices such as problem-solving procedure, Socratic Questioning and Dialogical Discussion.

\section{(4) Habits of mind}

To be a critical thinker, not only should one have the intellectual resources necessary for critical thinking, but one also must have certain commitments, attitudes or habits of mind that dispose him/her to use these resources to fulfill relevant standards and principles of good thinking (Bailin et al., 1999). Some attitudes or commitments that have been characterized by Paul (1990) and Bailin et al. (1999) include respect for reasons and truth, open-mindedness, fairmindedness, independent-mindedness, and an intellectual work-ethic.

\section{CRITICAL THINKING AND LEARNER AUTONOMY}

Critical thinking has also something to do with the concept of learner autonomy. Autonomy lies at the very center of Enlightenment thinking began in the (European) Enlightenment period (Schmenk, 2005). Most notably, it was the philosopher Kant (1933, as cited in Schmenk, 2005) who developed the concept of personal autonomy to characterize the human potential to make rational decisions individually while respecting other persons' autonomy. Autonomy does not, therefore, imply freedom of action on any given occasion, but rather a more general idea that the individual should "freely direct the course of his or her own life" (Young 1986, as cited in Benson, 2008). As such, the concept of autonomy defines the senses in which a liberal society should value and protect individual freedom (Benson, 2008; Trebbi, 2008). The emergence of the Enlightenment ideals of autonomy and independence, and its subsequent application in education, recognizes the right of individuals to use their own capacity to make reasonable decisions of and on their own to think and act independently, be able to resist domination and move toward emancipation (Schmenk, 2005, Trebbi, 2008). Critical thinking with its libratory promise paves the way to achieve the ideal of emancipation as Brookfield (1988, as cited in Garrison, 1991) suggests emancipatory learning "places critical thinking squarely in the context of adult life".

\section{CRitical Thinking/Thinker AND Instructional Process}


To enhance critical thinking, we should not simply make our students master information, but we should also help them develop an unceasing process of thinking about that information. If we teach students this way, they will realize that their field of study is not merely a repertoire of knowledge to be memorized. Instead, they come to realize that each discipline is a dynamic, creative thinking process. If students learn "how to think", they will know new ways of perceiving the world around themselves.

Now one question arises: Should critical thinking be addressed as a distinct subject or it may be regarded as an indispensible part of specific disciplines? Glaser (1984, as cited in Garrison, 1991) holds that "as individuals acquire knowledge, they also should be empowered to think and reason." In short, as McPeck (1981, as cited in Garrison, 1991) believes "there is no universal skill properly to be called critical thinking"; therefore, critical thinking skills are not generalizable and are specific to the context in which the process is exercised. Accordingly, if we take the idea put forward by McPeck, we can teach critical thinking in much the same way that other skills are teachable, namely, through drills, exercises or problem solving in an area.

Considering that critical thinking skills are best developed contextually within certain disciplines, the most challenging responsibility lies with the teacher. Teacher's role is to both encourage and develop critical thinking skills. Learners may find resources and even organize their own learning processes, but breaking out of deeply-rooted longheld beliefs, mindsets, or perspectives about the way things are, entails an unusual ability and discipline (Garrison, 1991). Hence teacher plays the role of a facilitator in that $\mathrm{s} / \mathrm{he}$ encourages the learner to challenge ideas, beliefs and norms through collaborative dialogue, to accept responsibility for their own leaning, to examine ideas and issues and to make worthy judgments. In fact, all this process of contextual development of critical thinking takes place through what Brookfield (1987, as cited in Garrison, 1991) calls a "learning conversation" in that both teacher and learner are involved in a reciprocal interactive challenge for which they need to take risk, be spontaneous and resolve their disagreements.

The "learning conversation" phrase mentioned earlier places emphasis on the importance and necessity of dialogic discussion between teacher and student. If we recall what King (1995) conceives of a critical thinker as an inquiring mind who asks thought-provoking questions, then as Glaser (1984, as cited in Garrison, 1991) states "interactive inquiry methods are powerful tools for teaching thinking in the context of subject matter" since they help teachers develop a critical spirit in students. However, as Siegel (1988, as cited in Garrison, 1991) believes, helping students develop their own critical spirit happens if their teachers adopt a critical manner in the first place. In other words, teachers should be willing to subject all his/her own beliefs and practices to scrutiny and critical analysis, and so to allow students the genuine opportunities to understand the role reasons play in the justification of thought and action. In short, the most important role of the teacher is to model critical thinking. This critical spirit does not realize provided that teachers may themselves freely participate in critical discussion in the first place. As such, critical thinking is challenging to teach and model. It puts greater demands on faculty and students than traditional education.

\section{CRITICAL THINKING IN IRANIAN EFL CONTEXT}

It is discouraging to know that despite all efforts and costs of foreign language teaching in Iran, students suffer from difficulties in language learning skills (Fahim \& Sa'eepour, 2011). The problem seems, as Shuffersman (1991) was quoted earlier, to be lying with the educational system that teachers, still informed by the traditional mindset, do their best to teach "what to think" rather than "how to think" effectively about the subject matters. In fact in such educational system, students gain lower order learning skills such as associative and rote memorization resulting in misunderstanding, prejudice, and discouragement in which students develop techniques for short term memorization and performance (Paul, 1990). These techniques hamper the students' thinking seriously about what they learn.

Unfortunately, the situation in Iran is not a dissimilar one. Iranian students are not educated as critical thinkers in their first language educational system since teachers, based on traditional teaching framework, disregard the learners' views and opinions and do not give them the chance to express themselves. Consequently, students do not learn to use their thinking skills (Fahim \& Sa'eepour, 2011).

Despite this, efforts have been being made across the country in recent years firstly to investigate the issue of critical thinking and its relationship with other constructs, and secondly to find out whether teaching critical skills could help students improve their language proficiency.

Sheikhy Behdani (2009) conducted a research study exploring the relationship between autonomy, critical thinking ability, and reading comprehension of the Iranian EFL learners. The results showed that there existed a significant relationship between critical thinking ability of learners and their performance on reading comprehension; simply put, the higher the critical thinking ability, the higher the reading comprehension. The findings of the study also indicated that critical thinking and autonomy of students were highly correlated.

In another study, the relationship between critical thinking and lexical inferencing of EFL learners was examined by Mirzaie (2008). Here, the researcher found out there was a relationship between critical thinking levels and lexical inferencing of learners. The study confirmed that when confronted with unknown words while reading, those learners who had higher levels of critical thinking demonstrated more ability of lexical inferencing.

Kamali and Fahim's (2011) study investigated the relationship between critical thinking ability, resilience, and reading comprehension of texts containing unknown vocabulary items. To them, resilience, which is a newly-developed 
psychological construct considered as a personality factor of individual learners, has come to mean "a measure of successful stress-coping ability" (Connor \& Davidson, 2003, as cited in Kamali \& Fahim, 2011), which enables individuals to overcome difficult or traumatic circumstances and grow up to become healthy, educated, and successful citizens. In fact, tackling stressful challenging and demanding world in which individuals, and L2 learners in particular, live is required to obtain academic and social success. The results of their study revealed that there is a significant relationship between critical thinking ability, resilience, and reading comprehension suggesting that good internal resources such as high levels of critical thinking ability and resilience can affect academic performance, i.e. competence in reading, and may be considered as protective factors among L2 readers. Their findings also suggest that the presence of such a strong relationship may be due to the fact that critical thinking and reading are both cognitive abilities which have some identifiable cognitive skills in common.

Still in another research, Fahim and Sa'eepour (2011) conducted a study intending to investigate the impact of teaching critical thinking skills on reading comprehension ability, as well as the effect of applying debate on critical thinking of EFL learners. Their findings showed that incorporating critical thinking skills in language classroom is vital to improve language teaching and learning. They concluded that every effort students made including being involved in reading materials, searching different sources, sharing opinions with others, cooperating in the classroom, and taking part in the argumentation for debate was a considerable contribution to triggering their thinking skills, in other words, activating their cognitive ability which led to the improvement of their reading comprehension. In fact, their results are in line with the studies confirming the positive relationship between critical thinking ability and language proficiency indicating that teaching critical thinking skills in EFL context can improve language learning.

Furthermore, Nikoopour et al. (2011) carried out a study investigating the relationship between critical thinking and the use of direct and indirect language learning strategies by Iranian learners. Results from their study showed that critical thinkers did show a significant relationship with the overall direct language learning strategies on the one hand. The critical thinkers, on the other hand, showed a significant relationship with cognitive strategy. In other words, critical thinkers preferred the cognitive language learning strategies. However, no significant relationship was found between critical thinking and other direct strategies that are compensation and memory strategies. As far as the relationship between critical thinking and indirect language learning strategies is concerned, the findings of the study indicate that critical thinkers preferred the metacognitive and social language learning strategies. However, no significant relationship was found between critical thinking and the other class of indirect strategies; that is, affective language learning strategies.

In another research study, Fahim \& Azarnioushi (2011) tried to see whether there is any relationship between the critical thinking ability of language learners and their performances using rule driven/ discovery learning approaches to teaching grammar. The results of the results of their study showed that there was a positive correlation between the critical thinking ability of the learners and their grammar test scores in the inductive period. However, as for the deductive teaching method, no special relationship could be found between the critical thinking ability of the learners and their grammar test scores. In other words, the results of the study indicated that learners with a higher critical thinking ability prefer inductive methods of teaching grammar while in deductive methods of teaching grammar, there seems to be no difference between learners with high or low critical thinking abilities.

The findings of a study conducted by Khorasani and Farimani (2010) suggest that the Iranian educational setting is more or less in line with the old metaphor of "teacher as both a full container and a funnel, and learner as an empty container", and does not support educational practitioners in their educational endeavors towards training critical thinkers and autonomous learners. Furthermore, the educational books currently used in the Iranian schools do not support critical thinking either; therefore, critical thinking is not in large part regarded as an educational goal. In another study Jamshidian and Farahani (2010) showed that there is no significant relationship between critical thinking and either gender or the age of the learners. Despite this, it is still a question why in this single setting we have different learners in term of being critical or non-critical thinkers, and why do we still have critical thinkers in Iran in the first place?

According to Khorasani and Farimani (2010), the reason we have both critical thinkers and non-critical thinkers in the Iranian setting is that, and in spite of books playing as the non-critical-thinking-inducing variable, the whole educational agenda is more of a teacher-dependent entity. Things in the classroom are defined and refined by teachers. The majority of teachers are themselves brought up by this old view of education and view education mainly as filling their students' memory banks with bits of information, so they cannot take their students any further than what they themselves are. But there are teachers who do not belong to the mainstream view of education and do not consider themselves as the only voice in the classroom (Pishghadam, 2008). Khorasani and Farimani (2010) showed that teachers, who come from democratic families, favor divergent thinking, organize and lead both political, social and scientific discussions, and try to have as many voices as possible in the classrooms instead of them being the only voice, are able to sow seeds of critical thinking in their students. This latter group of teachers do their best prepare the classroom atmosphere in such a way that students can (learn to) express their own ideas. They make the same books and educational materials but with a different attitude. As such, critical thinkers in Iran are not formally and officially trained to be critical thinkers, and critical thinking is in fact a style whose status varies from person to person depending on the training learners received from various teachers. 


\section{CONCLUSION}

Teaching Critical Thinking - the movement resting on the idea that schools should be less concerned with imparting information and requiring the memorization of empirical data - marks a new chapter in today's education since in an ever-changing world where almost nothing can be taken on faith for long, "critical thinking" seems to be a solution (Birjandi \& Bagherkazemi, 2010). Dealing with the extraordinary challenges of today's information society which is based on producing and promoting knowledge requires citizens equipped with "critical competence" (Feuerstein, 1999). Within such framework, ameliorating students' meta-knowing should be a focal point in the curriculum in order to enable these individuals to form autonomous outlooks on life (Gordon, 1995, as cited in Feuerstein, 1999). Drawing learners' attention to the different purposes of critical thinking can help achieve more collaborative and constructive approaches to thinking, learning and assessment (Smith, 2011).

From the evidence of the various studies mentioned earlier, some implications may be drawn. Informed by the study conducted by Kamali and Fahim's (2011) whose findings indicated that levels of critical thinking have significant effects on both resilience and reading ability of texts with unknown words, it can be concluded that the utilization of critical thinking strategies would help learners read more effectively and improve their resilience and stressmanagement skills. Therefore, it is crucial for EFL/ESL teachers to encourage students to use their thinking abilities and provide them with challenging opportunities to reflect, grow, and learn. In other words, it is the responsibility of teachers to educate students for inquiry, problem solving, critical and creative thinking, and reflection which can contribute to their progress in language learning (Kamali \& Fahim, 2011); however, students should also be made aware that the discreetly personal critical thinking is crafted at one's own pace and to one's own taste.

The prime pedagogical suggestion would be directed for syllabus designers and materials developers since language learners are in dire need of course books and materials that invoke critical thinking. Therefore, materials developers need to not only make an effort to create lessons that promote critical thinking as one of the effective elements in both academic and future career success and encourage students to reflect on their progress and take charge of their own thinking, but also include critical thinking issues as an essential aspect in teacher education since they have an enormous responsibility in the classroom (Birjandi \& Bagherkazemi, 2010). Teachers' effective use of questions, involving students in discussions over challenging and motivating topics and various forms of reflection conducted on the basis of mutual respect could engage students in meaningful critical thinking processes (Rezaei et al., 2011). Hence, materials developers should incorporate activities and practices which stimulate and build features of critical competence, preparing both learners and teachers to function well in the society as competent, autonomous, and accountable citizens.

The next suggestion would implicate the Iranian education department. They can do two things: firstly to include critical thinking as one of the requirements for the future employment, and secondly to hold in-service training classes to hone critical thinking skills of the incumbent teachers.

\section{REFERENCES}

[1] Bailin, S., Case, R., Coombs, J. R., \& Daniels, L. B. (1999). Conceptualizing critical thinking. Journal of Curriculum Studies, $31(3), 285-302$.

[2] Benson, P. (2008). Teachers' and learners' perspectives on autonomy. In T. Lamb \& H. Reinders (Eds.) Learner and teacher autonomy: Concepts, realities, and responses (pp. 15-32). Amsterdam: John Benjamins Publishing Company.

[3] Birjandi, P., \& Bagherkazemi, M. (2010). The relationship between Iranian EFL teachers' critical thinking ability and their professional success. English Language Teaching, 3(2), 135-145.

[4] Chaffee, J. (1992). Teaching critical thinking across the curriculum. New Directions for Community Colleges, 77, 25-35.

[5] Carpenter, C. B., \& Doig, J. C. (1988). Assessing critical thinking across the curriculum. In J. H. McMillan (Ed.) Assessing students' learning (pp. 33-46). San Francisco: Jossey-Bass.

[6] Fahim, M., \& Azarnioushi, S. (2011). The relationship between critical thinking and deductive/inductive teaching of grammar to Iranian EFL learners. The Iranian EFL Journal, 7(2), 180-195.

[7] Fahim, M., \& Sa'eepour, M. (2011). The impact of teaching critical thinking skills on reading comprehension of Iranian EFL learners. Journal of Language Teaching and Research, 2(4), 867-874.

[8] Feuerstein, M. (1999). Media literacy in support of critical thinking. Learning, Media and Technology, 24 (1), $43-54$.

[9] Garrison, D. R. (1991). Critical thinking and adult education: A conceptual model for developing critical thinking in adult learners. International Journal of Lifelong Education, 10 (4), 287 - 303.

[10] Huitt, W. (1998). Critical thinking: An overview. Educational Psychology Interactive. Retrieved June 2011 from http://chiron.valdostaedu/whuitt/col/cogsys/critthnk.html.

[11] Jamshidian, G. T., \& Farahani, K. A. A. (2010). The relationship between mother tongue, gender, age and critical thinking. Foreign Language Research, 55, 71-86.

[12] Kamali, Z., \& Fahim, M. (2011). The relationship between critical thinking ability of Iranian EFL learners and their resilience level facing unfamiliar vocabulary items in reading. Journal of Language Teaching and Research, 2(1), 104-111.

[13] Khorasani, M. M., \& Farimani, M. A. (2010). The Analysis of critical thinking in Fariman's teachers and factors influencing it. Journal of Social Science of Ferdowsi University, 6(1), 197-230.

[14] King, A. (1995). Inquiring minds really do want to know: Using questioning to teach critical thinking. Teaching of Psychology, $22(1), 13-17$. 
[15] Kuhn, D. (1999). A developmental model of critical thinking. Retrieved June 2011 from http://edr.sagepub.com/cgi/content/abstract/28/2/16

[16] Mirzaie, Z. (2008). The relationship between critical thinking and lexical inferences of Iranian EFL learners. Unpublished master's thesis, Islamic Azad University, Science and Research Campus, Tehran, Iran.

[17] Nikoopour, J., Amini Farsani, M., \& Nasiri, M. (2011). On the relationship between critical thinking and language learning strategies among Iranian EFL learners. Journal of Technology \& Education, 5(3), 195-200.

[18] Paul, W. R. (1990).Critical thinking: What every person needs to survive in a rapidly changing world. Retrieved June 2011 from www.amazon.com/Critical-thinking-survive-rapidly-changing/

[19] Pishghadam, R. (2008). Improving critical thinking through literary discussions in English classrooms. Journal of Science and Research of Mashhad University, 40(4), 153-167.

[20] Rezaei, S., Derakhshan, A., \& Bagherkazemi, M. (2011). Critical thinking in language education. Journal of Language Teaching and Research, 2(4), 769-777.

[21] Schafersman, S. D. (1991). An introduction to critical thinking. Retrieved July 2011 from http://www.freeinquiry.com/criticalthinking.html

[22] Schmenk, B. (2005). Globalizing learner autonomy. TESOL Quarterly, 39 (1), 107-118.

[23] Sheikhy Behdani, R. (2009). The relationship between autonomy, critical thinking ability, and reading comprehension of the Iranian EFL learners. Unpublished master's thesis, Islamic Azad University, Science and Research Campus, Tehran, Iran.

[24] Simpson, E., \& Courtney, M. (2002).Critical thinking in nursing education: A literature review. Retrieved June 2011 from eprints.qut.edu.au/263/1/SIMPSON_CRITICAL_THINKING.PDF

[25] Smith, E. (2011). Teaching critical reflection. Teaching in Higher Education, 16 (2), 211 - 223.

[26] Trebbi, T. (2008). Freedom - a prerequisite for learner autonomy? Classroom innovation and language teacher education. In T. Lamb \& H. Reinders (Eds.) Learner and teacher autonomy: Concepts, realities, and responses (pp. 33-46). Amsterdam: John Benjamins Publishing Company.

Mansoor Fahim was born in Nahavand in 1946. He received a Ph.D. in TEFL from Islamic Azad University in Tehran, Iran in 1993. As for his professional background, he was a member of the faculty of English Language and Literature at Allameh Tabataba' $i$ University in Tehran, Iran from 1981 to 2008 when he was retired as an associate professor of TEFL. At present, Dr. Fahim runs Research methods, Psycholinguistics, Applied Linguistics, Second Language Acquisition, and Seminar classes at MA level, and First Language Acquisition, Psycholinguistics, and Discourse Analysis courses at PhD level at a number of universities including Allameh Tabataba'i and Islamic Azad Universities, Science and Research Campus, Tehran, Iran. He has also published several articles and books mostly in the field of TEFL and has translated some books into Farsi.

Mehrshad Ahmadian was born in Sari in 1975. He is currently doing his PhD studies in TEFL at Islamic Azad University, Science and Research Campus, Tehran, Iran. He is a faculty member at Islamic Azad University, Qaemshahr Branch, Iran. His main interests are language testing and assessment, translation studies, and teaching oral skills. 